\title{
Effects of interstimulus interval length on short-and long-term habituation of autonomic components of the orienting response
}

\author{
ROBERT J. GATCHEL \\ University of Texas at Arlington, Arlington, Texas 76019
}

\begin{abstract}
The effects of two different interstimulus interval lengths (20-sec vs. 100-sec) on short- and long-term habituation of autonomic components of the orienting response (OR) were investigated in a study employing 24 subjects. Results indicated that the 20 -sec interval length was associated with increased short-term habituation and decreased long-term habituation, relative to the longer, 100-sec interval length. There was also a statistically near-significant association between interval length and magnitude of the OR to a subsequently presented novel dishabituating stimulus. These results suggest the presence of two active habituation processes.
\end{abstract}

Thompson and Spencer (1966), in outlining parametric characteristics of the habituation process, suggest that interstimulus interval (ISI) length significantly affects the degree of response habituation to a repetitive stimulus. In support of this contention, it has been demonstrated in human subjects that shorter ISI lengths are associated with increased relative habituation of autonomic components of the orienting response (OR) (Gatchel \& Lang, 1974; Raskin, Kotses, \& Bever, 1969). The experiment by Gatchel and Lang (1974) compared heart-rate and electrodermal habituation to a moderate-intensity tone across a range of ISI lengths. Results indicated that the amplitude of the phasic skin-conductance and heart-rate deceleratory responses, both indices of the OR, habituated more rapidly with shorter ISIs.

ISI length has also been shown to affect startle-response habituation in the rat (Davis, 1970). Davis found that tone exposure at a short, 2-sec ISI length, resulted in a greater decrement in responding than exposure at a longer 16-sec ISI length. The interesting finding of this experiment, however, was that when rats were tested $1 \mathrm{~min}$ or $24 \mathrm{~h}$ later with a variety of ISIs, habituation was greater at each test interval for the group trained on the longer, 16-sec ISI schedule. Davis, therefore, concluded that both short- and long-term habituation processes may be distinguishable. Long-term habituation was directly related to ISI length, while short-term habituation was inversely related to ISI length.

The high-intensity stimulus employed in the Davis (1970) experiment was designed to, and did, elicit a startle defensive response (DR). The process investigated was thus that of DR habituation. An important question which merits investigation is whether short- and

This research was supported in part by a grant to the author from the Liberal Arts Organized Research Fund, University of
Texas at Arlington. long-term habituation of the OR may similarly be distinguishable, since it has been speculated that the underlying mechanism involved in the $\mathrm{OR}$ may be different from that involved in the DR (Graham, 1973). The present experiment was, therefore, designed to examine whether ISI length differentially affects shortand long-term habituation of autonomic components of the OR in human subjects. The effect of this ISI parameter on the subsequent reappearance of the OR to a novel, dishabituating stimulus was also examined.

\section{METHOD}

\section{Subjects}

Subjects consisted of 24 male undergraduates from the introductory psychology subject pool at the University of Texas at Arlington. They received points to be applied to their course grade for participation in this experiment. All subjects reported having normal hearing.

\section{Apparatus}

Heart rate and skin resistance were continuously monitored throughout the experiment on a Model 6 Physiograph. Miniature Beckman silver-silver chloride electrodes were attached to the skin over the anterolateral lower ribs to monitor heart rate on a Physiograph cardiotachometer. Beckman silver-silver chloride electrodes $(1 \mathrm{~cm}$ radius) were attached to the palm and ventral side of the wrist of the subject's nonpreferred hand to record skin resistance. Beckman electrode paste was used as the electrolyte. A Physiograph GSR coupler imposed a current of 10 microA through the two electrodes. Two channels of electrodermal data were collected. The first channel was dc-coupled and recorded tonic skin-resistance levels at a low sensitivity setting $(2,500-\mathrm{ohm}$ resistance change sensitivity). The second channel was capacitor-coupled, with a 6-sec time constant, which allowed the recording of short-term phasic responses at a high sensitivity setting $(500 \mathrm{ohm}$ resistance change sensitivity).

Stimuli were 2 -sec tones presented binaurally over a matched set of Grason-Stadler earphones. The tones were generated by a Hewlett-Packard $200 \mathrm{CD}$ oscillator, with a Grason-Stadler Model 829E electronic switch imposing a 10-msec rise and decay time on the tones. The tone intensity was $65 \mathrm{~dB}$, as measured by scale Cs of a General Radio Company sound-level meter 
(Type 1565-A). The 2-sec tone presentation was controlled by a Scientific Prototype interval timer.

\section{Experimental Design}

An experimental paradigm similar to that employed by Davis (1970) was used to examine the effects of ISI length on shortand long-term habituation. In this paradigm, the ISI length conditions of training are different for different groups, but subsequent ISI test conditions are identifical for all groups. This procedure avoids confounding the test interval with the training interval.

Subjects were randomly assigned to one of two ISI groups (12 subjects per group). Group 1 subjects were administered tones every $20 \mathrm{sec}$ during Part I of this experiment. Group 2 subjects were administered tones every $100 \mathrm{sec}$. Each subject received 15 tones. For half of the subjects in each group, the frequency level of the tone was $500 \mathrm{~Hz}$; for the other half, it was $1,000 \mathrm{~Hz}$. The intensity was set at $65 \mathrm{~dB}$ for both tone frequencies.

In Part II of the experiment, which tested for long-term habituation effects, all subjects were administered the tones using both $20-\mathrm{sec}$ and $100-\mathrm{sec}$ ISI lengths. The sequence of ISI lengths was randomly determined. Each subject received 15 tones. At the completion of Part II, subjects received five presentations of a dishabituation tone. For those subjects who received the $500-\mathrm{Hz}$ tone during Parts I and II, the dishabituation tone was $1,000 \mathrm{~Hz}$; those subjects who had received the $1,000-\mathrm{Hz}$ tone during Parts I and II were administered the $500-\mathrm{Hz}$ tone during dishabituation. The ISI length during dishabituation was $60 \mathrm{sec}$.

\section{Procedure}

The subject was seated in a comfortable chair in a partially soundproof room. After the recording electrodes were attached, the experimenter calibrated the recording equipment in an adjacent room. The experimenter then read instructions which informed the subject that he would hear a series of tones. He was instructed to sit quietly, but not fall asleep, and to move as little as possible. The experimenter then left the room and, after a 15-min baseline period, presented the stimuli. At the completion of Part I of the experiment, the subject was given a 15 -min rest period. Part II of the experiment was initiated at the completion of the rest period. There was no rest period between Part II and the dishabituation test trials.

\section{Data Reduction and Analysis}

Phasic skin-resistance response measures were transformed to units of $\log$ conductance using the formula: $\log \left(1 / R_{1}\right)-\log$ $\left(1 / R_{2}\right)$, where $R_{1}$ is the maximum resistance deflection peak occurring within $5 \mathrm{sec}$ of stimulus onset, and $R_{2}$ is the prestimulus resistance base level. Tonic skin-resistance levels were measured prior to the onset of each stimulus, and converted to conductance units. The degree of initial deceleration was used as the measure of the heart-rate component of the OR, as suggested by Graham and Clifton (1966). This measure was computed by finding the difference between the average of the two prestimulus heart beats and the slowest of the first three poststimulus heart beats. The heart-rate recordings were corrected for the one-beat lag inherent in cardiotachometer readings.

The skin-resistance and heart-rate-response components were measured by scorers who had no knowledge of the experimental contingencies of the present study. The component measures were punched on computer cards for computation of the above-described transformations and later statistical analyses on an IBM 370 computer.

\section{RESULTS}

All data were analyzed by a one between-(groups) and

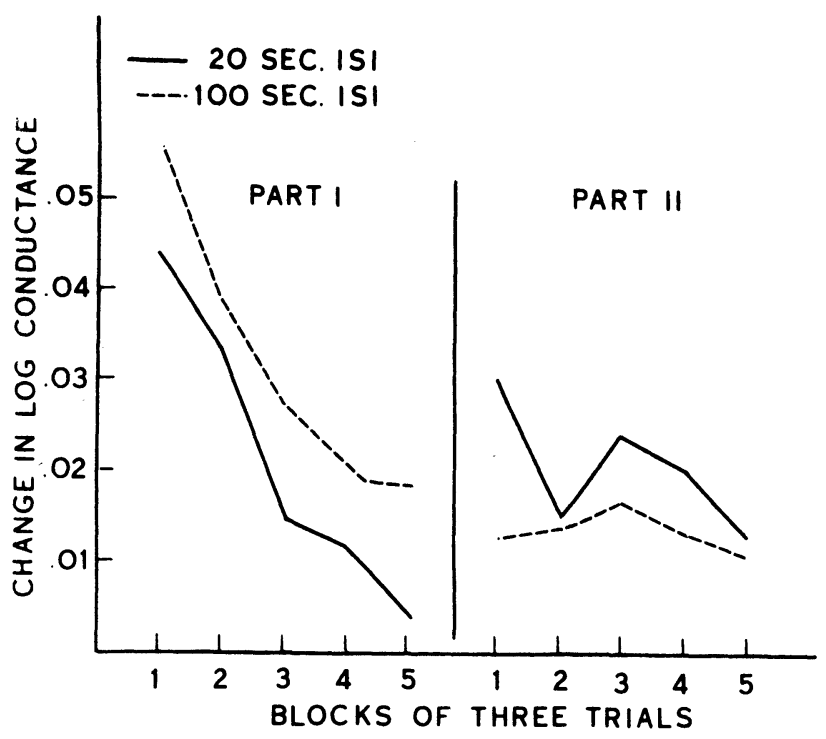

Figure 1. Average skin-conductance response curves for groups over trials.

one within-(trials) subjects analysis of variance.

Figure 1 plots the mean phasic skin conductance response curves for groups over trials, for Parts I and II. They are plotted in blocks of three trials. This figure shows that the short-ISI group is associated with greater habituation in Part I and initially less habituation in Part II, relative to the long-ISI group. Analyses of variance confirmed these results. In Part $I$, there was a significant trials effect, $F(14,308)=6.63, p<.001$, indicating the occurrence of habituation over trials. More importantly, there was a significant Group by Trials effect, $F(14,308)=2.01, \mathrm{p}<.01$, which statistically confirms that ISI length differentially affects rate of habituation over trials. In Part II, there was a significant Group by Trials effect, $F(14,308)=2.85$, $\mathrm{p}<.01$. This result indicates that the short-ISI group demonstrated greater responding at the start of Part II, i.e., less long-term habituation.

Table 1 lists the mean skin conductance responses for each group over the five dishabituation test trials. Analysis of variance yielded a significant trials effect, $F(4,88)=2.94, p<.05$, which statistically confirms that habituation occurred over the five trials. There was also

Table 1

Average Skin Conductance Response Magnitudes for Each ISI Group Over the Five Dishabituation Trials

\begin{tabular}{ccc}
\hline & \multicolumn{2}{c}{ Average } \\
\cline { 2 - 3 } Trials & 20-Sec ISI & 100-Sec ISI \\
\hline 1 & .0485 & .0341 \\
2 & .0247 & .0124 \\
3 & .0215 & .0150 \\
4 & .0124 & .0129 \\
5 & .0224 & .0176 \\
\hline
\end{tabular}




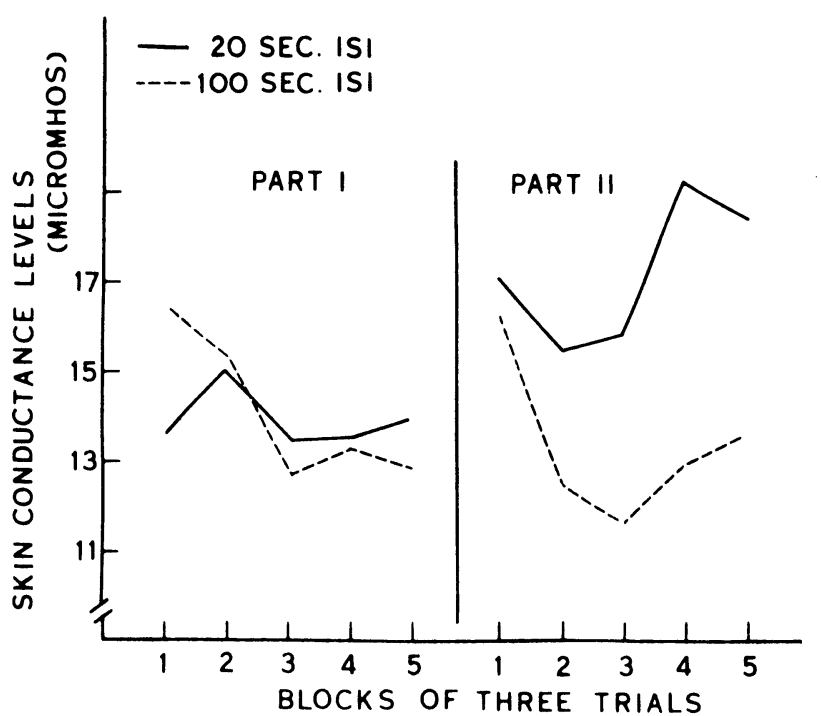

Figure 2. Average skin-conductance levels for groups over trials.

a near significant Group by Trials effect, $F(4,88)=2.01$, $\mathrm{p}<.10$, indicating a tendency for the short-ISI group to demonstrate larger responses to the initial presentations of the dishabituation stimulus, relative to the long-ISI group.

\section{Skin-Conductance Level}

Analysis of variance indicated no significant initial skin-conductance level differences between groups prior to the first tone presentation.

The mean prestimulus skin-conductance levels of the two groups over trials are shown in Figure 2. In Part I, the graphic presentation of the data suggests that the long-ISI-length group is associated with a greater decrement in tonic skin-conductance levels over trials. This effect, however, was statistically nonsignificant. Analysis of variance of Part II data did yield significant trials, $F(14,301)=2.27, p<.01$, and Group by Trials, $F(14,301)=1.87, p<.05$, effects, which confirm that the long-ISI group demonstrated a greater decrement in tonic levels over trials. During the dishabituation test trials, the long-ISI group continued to show lower skin conductance levels compared to the short-ISI group; this effect, however, was statistically nonsignificant.

\section{Heart Rate}

Analysis of variance indicated no significant heart-rate base-level differences between groups prior to the presentation of the first stimulus.

Figure 3 presents the mean heart-rate deceleratory responses over trials for the two experimental groups. As can be seen, there are significant differences in rate of habituation during Part I, with the short-ISI group demonstrating a greater decrease in responding.over trials. Analysis of variance confirmed these Part I findings, yiclding significant trials, $F(14,301)=1.96$, $\mathrm{p}<.05$, and Group by Trials, $\mathrm{F}(14,301)=2.11, \mathrm{p}<.01$, effects, and a near-significant overall group effect, $F(1,11)=4.15, p<.10$. There were no significant effects found in Part II nor during the dishabituation test trials

\section{DISCUSSION}

The results of the present experiment clearly demonstrate that ISI length differentially affects shortand long-term habituation of autonomic components of the OR. In Part I, tone exposure at the short, 20-sec, ISI length resulted in greater habituation of heart-rate and skin-conductance responses than exposure at the longer, 100 -sec, ISI length schedule. This effect has been previously reported by Gatchel and Lang (1974) and Raskin et al. (1969). The most theoretically important finding of the present experiment, however, was that when the groups were tested 15 min later with both 20 and 100 -sec ISIs, skin-conductance response habituation was greater for the long-ISI group. Thus, similar to the study by Davis (1970) on DR habituation, long-term OR habituation was directly related to ISI length while short-term habituation was inversely related to ISI length.

There was also a statistically near-significant effect found between ISI length and the subsequent reappearance of the skin-conductance response component of the $\mathrm{OR}$ to a novel, dishabituating stimulus. During the dishabituation test trials, the short-ISI group demonstrated greater magnitude of responding.

Unlike the skin-conductance response measure, the heart-rate deceleratory response was not found to be

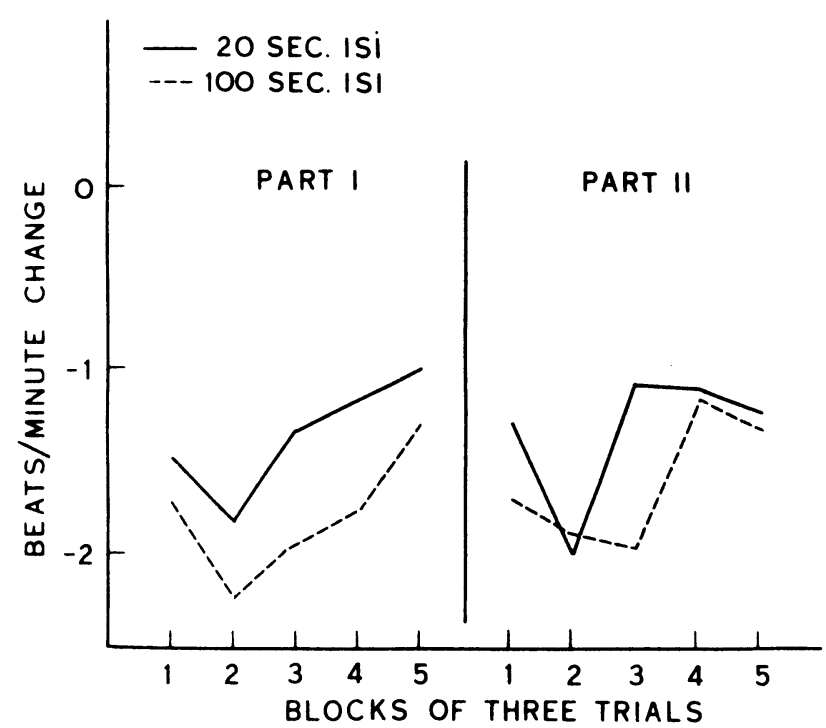

Figure 3. Average heart-rate deceleratory response curves for groups over trials. 
differentially affected by the ISI variable in Part II, or during the dishabituation test trials. This suggests that the heart-rate response may not be a sensitive measure by which to gauge the long-term habituation process. Skin conductance may be a more relevant measure because it is exclusively neural and correlates more closely with sympathetic arousal (Wang, 1964). It is sympathetic arousal level which may affect the consolidation process that prompts habituation. This point will be returned to later in the discussion.

Paralleling the course of phasic skin conductance and heart-rate response habituation in Part I, tonic skin-conductance levels also appeared to be differentially affected by the ISI variable. Although not statistically significant, the short-ISI group demonstrated a smaller conductance level decrement than the long-ISI group. This same effect was found significant in the study by Gatchel and Lang (1974). ${ }^{1}$ The tonic skin-conductance differences were also maintained in Part II of the present study, with the short-ISI group demonstrating a significantly higher tonic level relative to the longer-ISI group.

As noted by Davis (1970), an inherent problem in any study which compares different ISI lengths is that the total time spent in the experimental situation is necessarily confounded with the ISI parameter. It could be argued that it is merely time spent in the experimental situation which differentially affects rate of habituation. However, Davis and Wagner (1969) report that this factor has no appreciable effect on subsequent startle responding in the rat. Similarly, in a study of skin-conductance response habituation in human subjects, Geer (1966) reported that length of initial rest period prior to the first stimulus presentation did not affect rate of habituation. Davis (1970) also presents data which demonstrate that the ISI length effect cannot be attributed simply to time differences spent in the experimental situation.

In a recent review, Graham (1973) suggests that two different inhibitory processes must be active in order to account for short- and long-term habituation differences, "one, a refractory process which decays relatively quickly and the other, a process which accumulates and/or consolidates with time, analogous to a learning process." Indeed, two such processes appear to be necessary in order to explain the habituation differences found in the present investigation.

In Part I, the high rate of stimulus input present in the short-ISI group may have resulted in too brief a time period to have allowed complete recovery of a response to one stimulus before the next succeeding stimulus was presented. There is evidence for the presence of an autonomic response refractory period (Graham, 1973). This may account for the greater short-term habituation demonstrated by the 20 -sec ISI group.

The high rate of stimulus input may have also generated and maintained an elevated level of sympathetic arousal in the short-ISI group. Results did demonstrate that, relative to the long-ISI group, this group was associated with a somewhat higher skin-conductance level by the end of Part I, which was significantly maintained in Part II. This higher level of arousal may have interfered with the consolidation process that prompts habituation, and may have potentiated responding on subsequent exposures to the test stimulus and the dishabituation stimulus. If this was indeed the case, then other techniques for eliciting sympathetic activity should similarly interfere with secondary habituation. Future investigations of this possibility will provide additional evidence which should more fully illuminate the mechanisms underlying shortand long-term habituation.

\section{REFERENCES}

Davis, M. Effects of interstimulus interval length and variability on startle-response habituation in the rat. Journal of Comparative and Physiological Psychology, 1970, 72, 177-192.

Davis, M., \& Wagner, A. R. Startle responsiveness after habituation to different intensities of tone. Psychonomic Science, 1968, 12, 337-338.

Gatchel, R. J., \& Lang, P. J. Effects of interstimulus interval length and variability on habituation of autonomic components of the orienting response. Journal of Experimental Psy chology, 1974, 103, 802-804.

Geer, J. H. Effect of interstimulus interval and rest-period length upon habituation of the orienting response. Journal of Experimental Psychology, 1966, 72, 617-619.

Graham, F. K. Habituation and dishabituation of responses innervated by the autonomic nervous system. In $H$. V. S. Peeke and M. J. Herz (Eds.), Habituation: Behavioral studies and physiological substrates. New York: Academic Press, 1973.

Graham, F. K., \& Clifton, R. K. Heart-rate change as a component of the orienting response. Psychological Bulletin, $1966,65,305-320$.

Raskin, D. C., Kotses, H., \& Bever, J. Autonomic indicators of orienting and defensive reflexes. Journal of Experimental Psychology, 1969, 80, 423-433.

Thompson, R. F., \& Spencer, W. A. Habituation: A model phenomenon for the study of neuronal substrates of behavior. Psychological Review, 1966, 73, 16-43.

Wang, G. H. The neural control of sweating. Madison: The University of Wisconsin Press, 1964.

\section{NOTE}

1. The smaller number of subjects employed in the present experiment may account for the failure to attain statistical significance.

(Received for publication July 11, 1974; accepted November 11,1974 .) 